\title{
Correction to: Epidemiology of patients presenting to a pediatric emergency department in Karachi, Pakistan
}

\author{
Nadir ljaz ${ }^{1}$, Matthew Strehlow ${ }^{1 *}$, N. Ewen Wang ${ }^{1}$, Elizabeth Pirrotta ${ }^{1}$, Areeba Tariq ${ }^{2}$, Naseeruddin Mahmood ${ }^{3}$ and \\ Swaminatha Mahadevan ${ }^{1}$
}

\author{
Correction to: BMC Emerg Med 18, 22 (2018) \\ https://doi.org/10.1186/s12873-018-0175-4
}

The ethics statement in this article [1] incorrectly states that the study was approved by the IRB of the National Institute of Child Health (NICH) in Karachi. Contrary to this statement, the authors received approval to complete the study from the director of the

Published online: 28 August 2020 $\mathrm{NICH}$, not the ethics committee. The authors also received approval from the IRB of Stanford University School of Medicine, who have confirmed that their ethics approval remains valid without approval from the IRB at the NICH in Karachi. The IRB at the NICH in Karachi has confirmed that the authors should have applied for ethics approval for this study and that they cannot provide retrospective approval. Given the noninvasive nature of the study, the opinion of the Stanford University School of Medicine IRB and the potential public health implications of the findings, the Editor and Publisher have decided to take no further action.

\section{Author details}

${ }^{1}$ Department of Emergency Medicine, Stanford University School of Medicine, 300 Pasteur Dr, Rm M121, Alway Building MC 5119, Stanford, CA 94305, USA. ${ }^{2}$ Honors Program in Medical Education, Northwestern University, Evanston, IL, USA. ${ }^{3}$ Department of Paediatrics and Child Health, Aga Khan University, Karachi, Pakistan.

\section{Reference}

1. Ijaz N, Strehlow M, Wang NE, Pirrotta E, Tariq A, Mahmood N, Mahadevan S. Epidemiology of patients presenting to a pediatric emergency department in Karachi, Pakistan. BMC Emerg Med. 2018;18(1):22.

\footnotetext{
The original article can be found online at https://doi.org/10.1186/s12873018-0175-4.

* Correspondence: strehlow@stanford.edu

'Department of Emergency Medicine, Stanford University School of

Medicine, 300 Pasteur Dr, Rm M121, Alway Building MC 5119, Stanford, CA 94305, USA

Full list of author information is available at the end of the article
}

(C) The Author(s). 2020 Open Access This article is licensed under a Creative Commons Attribution 4.0 International License, which permits use, sharing, adaptation, distribution and reproduction in any medium or format, as long as you give appropriate credit to the original author(s) and the source, provide a link to the Creative Commons licence, and indicate if changes were made. The images or other third party material in this article are included in the article's Creative Commons licence, unless indicated otherwise in a credit line to the material. If material is not included in the article's Creative Commons licence and your intended use is not permitted by statutory regulation or exceeds the permitted use, you will need to obtain permission directly from the copyright holder. To view a copy of this licence, visit http://creativecommons.org/licenses/by/4.0/ The Creative Commons Public Domain Dedication waiver (http://creativecommons.org/publicdomain/zero/1.0/) applies to the data made available in this article, unless otherwise stated in a credit line to the data. 